\title{
Effects of Mindset on Positive Illusions
}

\author{
Shelley E. Taylor \\ University of California, Los Angeles
}

\author{
Peter M. Gollwitzer \\ University of Konstanz
}

\begin{abstract}
S. E. Taylor and J. D. Brown's (1988) position that mentally healthy people exhibit positive illusions raises a dilemma: How do people function effectively if their perceptions are positively biased? Using Gollwitzer's deliberative-implemental mindset distinction, we assessed whether people in a deliberative mindset show less evidence of positive illusions than people in an implemental mindset. Participants completed a mindset task and assessments of mood, self-perceptions, and perceived (in)vulnerability to risk. Deliberation led to worsened mood, greater perceived risk, and poorer self-perceptions, relative to implementation; control (no mindset) participants typically scored in between. Study 3 demonstrated that the mindset manipulation corresponds to how people actually make decisions or implement them. Results suggest that people use relatively realistic thinking when setting goals and more positive thinking when implementing them.
\end{abstract}

Taylor and Brown (1988) proposed that a mentally healthy person is characterized not by accurate assessments of his or her personal qualities, realistic estimates of personal control, and a realistic outlook on the future but by positive illusions. Specifically, they maintained that people typically hold at least three mildly self-aggrandizing perceptions of themselves, the world, and the future: unrealistically positive self-perceptions, an illusion of personal control, and unrealistic optimism about the future. They argued that, instead of being maladaptive, these positively distorted perceptions actually foster the criteria normally associated with mental health: positive self-regard, the ability to care for and about other people, the capacity for creative and productive work, and the ability to effectively manage stress (Taylor, 1989; Taylor \& Brown, 1994).

Despite empirical support for the model, this portrait raises a disturbing question: If normal people's perceptions are marked by positive biases, how do they effectively identify and make use of negative feedback they may encounter in the world? If people are capable of explaining away, compartmentalizing, or otherwise dismissing or minimizing negative feedback, as

Shelley E. Taylor, Department of Psychology, University of California, Los Angeles; Peter M. Gollwitzer, Department of Psychology, University of Konstanz, Konstanz, Germany.

This research was supported by a grant from the National Institute of Mental Health (MH 42152) and funding from the Max Planck Society (Max Planck Institute for Psychological Research, Munich, Germany).

We thank Lien Pham (Studies 1 and 2), Juliane Malzacher, and Ute Bayer (Study 3) for their assistance in collecting and analyzing the data. Brett Pelham and Gabrielle Oettingen made valuable comments on an earlier draft of the article.

Correspondence concerning this article should be addressed to Shelley E. Taylor, Department of Psychology, 1283 Franz Hall, University of California, Los Angeles, California 90024-1563. Electronic mail may be sent via the Internet to taylor@psych.sscnet.ucla.edu or to gollwitz@soz.psychologie.uni-konstanz.de.
Taylor and Brown (1988) suggested, they may not process a large amount of useful feedback. Perhaps the self-serving illusions that bolster self-esteem and produce a positive mood in the short run ultimately set people up for disappointment and failure in the long run, precisely because the negative feedback they should have incorporated into their goal decisions and planning went ignored (cf. Janoff-Bulman \& Brickman, 1982; Weinstein, 1984).

One potential resolution Taylor and Brown (1988) raised is the possibility that there may be times when people are more honest with themselves, during which they recognize and incorporate negative feedback. Research on mindset by Gollwitzer and his associates (Gollwitzer, 1990, 1991; Gollwitzer, Heckhausen, \& Steller, 1990; Gollwitzer \& Kinney, 1989) suggests a set of circumstances when precisely this situation may occur. Drawing on Heckhausen's (1986) theory of action phases, Gollwitzer and his colleagues argued that the predecisional phase, when potential action goals entailed by a person's desires and wishes are deliberated, is characterized by a deliberative mindset. Because deliberation involves the careful appraisal of potentially competing goals, the weighing of likely pros and cons with respect to each potential goal, and consideration of the feasibility of these goals, it is expected to foster relatively evenhanded and accurate appraisal of evidence.

The postdecisional phase, when people plan the implementation of a chosen goal, is characterized by an implemental mindset. The implemental mindset is assumed to induce participants to muster motivation, resources, and cognitions in service of goal-directed actions, and thus, Gollwitzer $(1990,1991)$ predicted, it will lead people in the direction of cognitions that favor goal achievement. These cognitions may include those specific to the goal-directed actions to be implemented, as well as more general cognitions that constitute the environment for task implementation.

To examine these arguments, Gollwitzer and Kinney (1989, Study 2) put half of their participants into a deliberative mind- 
set by asking them to contemplate the pros and cons of making a major change in their lives. The other half was placed into an implemental mindset. These participants were asked to plan the implementation of a decision they had already made and to list when, where, and how they proposed to initiate goal-directed actions. Subsequent to the mindset manipulations, participants completed an ostensibly unrelated task that required them to estimate their degree of personal control. Specifically, they worked on a contingency learning task in which they tried to turn on a light by either pressing or not pressing a button (modeled after Alloy \& Abramson, 1979). The apparatus, in fact, produced noncontingent onset of the light. A control group performed the contingency task without any mindset manipulation. Participants in the implemental mindset condition inferred that they had successfully exerted personal control over the light task when light onset was frequent, whereas participants in the deliberative mindset condition did not succumb to this illusion-of-control effect. Moreover, Gollwitzer and Kinney found that control participants (those not in either a deliberative or implemental mindset) showed a significantly greater illusion of control than deliberative participants but tended to show less of an illusion of control than implemental participants.

These results imply that when people are deliberating potential action goals, they are less vulnerable to the illusion of control than when they plan the implementation of goal-directed actions. Do Gollwitzer and Kinney's (1989) results provide a more general context for resolving the conundrum created by positive illusions? That is, is deliberation generally a time when positive illusions are suspended, relative to implementation? There are several reasons why one cannot extrapolate directly from Gollwitzer and Kinney's study to the more general phenomenon of positive illusions. The illusion-of-control paradigm used in Gollwitzer and Kinney's studies is highly artificial (pressing buttons to turn on target lights). Because this situation is unfamiliar to participants, it may be relatively simple to affect responses to it by means of a mindset manipulation. The other illusions discussed by Taylor and Brown (1988), namely, selfaggrandizement and unrealistic optimism, may not be so easily influenced, because people's self-perceptions and beliefs about their personal futures may be more anchored in personal experience. For example, people should be highly familiar with their own cheerfulness, intelligence, kindness, and other personal qualities, and so such self-perceptions may not change greatly in response to variable factors such as mindset. A second factor that limits the generalizability of Gollwitzer and Kinney's studies to positive illusions more generally is the fact that Gollwitzer and Kinney addressed only uncontrollable outcomes. It is important to assess whether mindset affects the perceived controllability of outcomes that are under personal control. Third, Gollwitzer and Kinney's investigation leaves unclear the processes by which mindset affects the illusion of control. It may be that the effect is a direct one, based on the cognitive contents and procedures of a person's deliberations and thoughts related to implementation. Alternatively, it is possible that mindset affects mood, which in turn affects positive illusions. Mood has been argued to be a pathway by which positive illusions affect mental health (Taylor \& Brown, 1988). Mood may also be the most immediate consequence of circumstances that foster positive illusions and, as such, may act as the day-to-day manifestation of illusions in daily life (Taylor, Aspinwall, \& Giuliano, 1993).
Thus, additional exploration of the processes by which mindset may affect positive illusions is warranted. Finally, Gollwitzer and Kinney's studies leave unclear the question of whether people's spontaneous deliberations and implementations actually correspond to the processes manipulated in the mindset manipulation. That is, do people deliberate evenhandedly, as the deliberative mindset manipulation assumes, and, when they are focused on implementing a task, are their cognitions specific to implementation, as Gollwitzer and Kinney's manipulation implicitly assumes?

The present set of investigations was designed to address these questions. On the basis of Gollwitzer and Kinney's (1989) results, we argued that deliberation is a time when positive illusions are suspended, when people confront their talents and shortcomings and the resources and limitations of the environment realistically in attempting to decide whether a given action goal is fruitful and likely to be successful. As such, we predicted that mindset would influence self-perceptions and the perception of invulnerability to risk (unrealistic optimism) as well as the illusion of control. By contrast, implementation may be a time when positive illusions are mustered, even exaggerated, in service of the motivation needed to bring about goal achievement. We explicitly tested these predictions using measures of self-perception and perceived risk that correspond more readily to manipulations that have been used in previous studies of positive illusions (Taylor, 1989; Taylor \& Brown, 1988). In so doing, we sought to extend Gollwitzer and Kinney's results beyond the laboratory paradigm in which these effects were previously demonstrated. In addition, we assessed the potential role of mood as a mediator of the effects of mindset on positive illusions.

\section{Study 1}

In Study 1 we tested these predictions by manipulating mindset and observing its effects on tasks related to positive illusions. We also assessed the impact of deliberative and implemental mindsets on mood. Pretesting of the deliberative and implemental mindset manipulations suggested that the deliberative mindset induced a negative mood in many participants. An assessment of mood enabled us to see if mood might be a mediator whereby deliberative and implemental mindsets affect positive illusions, if such effects exist.

The study also explored unrealistic optimism about risk. At least 120 investigations have indicated that, when asked to evaluate their risk of succumbing to a wide variety of misfortunes relative to their peers, most people see themselves as less vulnerable (Weinstein, 1993). This illusion of invulnerability is both robust and pervasive, encompassing a wide variety of potentially threatening events. We predicted that a deliberative mindset would reduce people's tendency to see themselves as less vulnerable than others to an array of negative events, whereas an implemental mindset would enhance the perception that one is less vulnerable than others to negative events, relative to a control condition.

To further examine how mindset may affect positive illusions, we explored its impact on two dispositional measures. We included a measure of self-esteem (Rosenberg, 1965) to see if individuals in a deliberative mindset experience temporary losses in self-esteem. Self-esteem has previously been used as a proxy 
for positive illusions in other investigations (e.g., Aspinwall \& Taylor, 1992; Baumeister, Tice, \& Hutton, 1989). We also examined the effect of mindset on the Life Orientation Test (LOT), a dispositional measure of optimism developed by Scheier and Carver (1985), to see if mindset can induce temporary shifts in expectations about the future.

\section{Method}

\section{Participants}

Eighty-one participants ( 50 women and 31 men) were recruited individually by student experimenters in a research methods course. All were college students between 17 and 29 years of age, with a median age of 21 . A classroom of 22 psychology students, 18 women and 4 men, naive as to the purpose of the experiment and of a comparable age distribution as the participants in the mindset conditions, completed all dependent measures without completing the mindset tasks.' They constituted a control condition for the dependent measures against which the deliberative and implemental mindset conditions could be compared.

\section{Procedure}

Each individually run participant was approached by a student experimenter, and the experiment was carried out in a quiet setting free of distractions. Participants were first given verbal instructions to orient them to the experiment. They were told that the researchers were investigating the process of goal selection and implementation and had found that certain tasks help people to define and pursue their goals more effectively. They were told that they would be working on a predetermined mental exercise with respect to their personal goals that would enable the experimenters to evaluate these tasks further.

Both the oral instructions and the written instructions followed the procedures of Gollwitzer and Kinney (1989); they were translated from German by Gollwitzer and his associates. All translated materials and instructions were pretested on UCLA undergraduates and revised slightly to increase clarity and avoid confusion. ${ }^{2}$ Participants were then randomly assigned to either the implemental or deliberative mindset manipulation condition and given written instructions.

Deliberative mindset condition. For the deliberative mindset condition, participants were asked to name an unresolved personal problem. A brief description of these types of problems was given:

Such problems are characterized by the fact that you are not yet sure whether to take action in order to change things. You feel very uncertain and you ask yourself whether it might not be better to leave things as they are. This means that you haven't decided to take action, but you haven't decided against it either.

Participants were told that they should not select tasks easy to implement, those for which a decision was already made, or those for which a decision would probably never be reached. They were informed that the problem should be complex and take the form of "Should I . . or not?"

The analysis of the decision took three parts. Part A was concerned with the immediate consequences and long-term consequences of making a decision that involves a change. Immediate consequences were listed first, and then long-term consequences that could ensue from those immediate consequences were listed. For each positive and negative consequence, participants were asked to rate the certainty of occurrence in percentage. Part B asked participants to list the expected difficulties that might arise in trying to implement the decision involving the change. Part $C$ asked participants to list the immediate and longterm consequences of not making a decision, that is, of leaving things as they are. For both positive and negative consequences, they were asked to rate the certainty in percentage that the consequence would occur. Participants were given a sample packet, ostensibly completed by a previous participant, concerning the decision of "going on a vacation or not." They were then instructed to work on their own unresolved personal problem.

Implemental mindset condition. Participants in the implemental mindset condition received a similar packet of written instructions but instead were asked to describe an intended project. A description of such a project was provided:

Intended projects are set goals which people intend to realize someday. All intended projects have in common that people have decided to take action in this matter. They feel determined to achieve the project.

Participants were told that the intended project should be complex and one that could be achieved within the next 3 months. They were asked not to invent a new project for the purpose of the exercise but to use one for which they had already made a decision.

After naming the project, participants were informed that they would be writing down the implementation steps involved in the intended project. They were provided with a set of questions divided into two parts to assist them. In Part A, they were asked to list the five most important steps for bringing about the project. These were described as distinct behavioral episodes which, if successfully executed, should guarantee the achievement of the intended project. Part B was concerned with the planned execution of these steps. Participants were asked to list when, where, and how each step was to be performed.

A sample sheet with the example of "going on vacation," ostensibly completed by a prior participant, was provided. Participants were asked to examine the example carefully and then move on to the master sheet to describe their own personal intended project.

\section{Dependent Measures}

After completing the deliberative or implemental mindset task, the participants were given the dependent measures. First, they completed a mood scale consisting of seven adjectives taken from the Multiple Affect Adjective Checklist (MAACL; Zuckerman \& Lubin, 1965), which has been used in a previous empirical effort to assess mood (Aspinwall \& Taylor, 1993). They rated themselves on each adjective using a 7-point scale ranging from 1 (not at all) to 7 (extremely). The adjectives were happy, downhearted, upbeat, contented, upset, sad, satisfied, lonely, and distressed. A composite measure of mood was derived by subtracting the summed self-ratings on adjectives that reflected negative mood from the summed self-ratings on adjectives that reflected positive mood. Next, participants completed a measure of relative perceived risk derived from Perloff and Fetzer (1986). Specifically, on separate items, they were asked to rate themselves and the average college student of their gender as to the likelihood of experiencing each of five unpleasant future events. The items were: being in an automobile accident, becoming divorced, becoming depressed, developing a drinking problem, and being mugged. These ratings were completed on 7-point scales that ranged from 1 (not at all likely) to 7 (extremely likely). The measure of

\footnotetext{
'Because completion of the dependent measures took approximately $10 \mathrm{~min}$, whereas the mindset manipulation took $30-40 \mathrm{~min}$, it was decided, for purposes of economy, to run the control group in a group setting. In retrospect, this may have been a false economy, because it rendered the data collection circumstances of the control group somewhat different than those in the two mindset conditions, creating questions of comparability.

${ }^{2}$ For example, the phrase "change decision" translated from German did not make sense to participants, and so the phrase "a decision involving a change" was substituted.
} 
relative risk was obtained by subtracting total self-ratings from total "average college student" ratings, thus yielding a measure of relative invulnerability to risk. If participants see themselves and the average college student of their age and gender as equally vulnerable, then their scores on the risk measure should both be 0 ; to the extent that participants see themselves as more invulnerable to risk than others, the resulting score will be positive.

Next, participants completed the Rosenberg Self-Esteem Scale (Rosenberg, 1965). This measure includes 10 statements reflecting self-attitudes (e.g., "On the whole, I am satisfied with myself"), and participants indicated on a 5-point scale that ranged from 1 (not at all) to 5 (very much) how much they agreed with each of the statements. The last measure was the LOT. Participants answered eight target items and four filler items on 5-point scales ranging from 1 (strongly disagree) to 5 (strongly agree). Sample items include the statements "If something can go wrong for me, it will" and "I'm always optimistic about my future".

After participants completed the dependent measures, the experimenter conducted a short postexperimental interview to assess participants' reactions to the experiment and to probe for suspicion. No participant expressed suspicion over the nature of the study. Participants were then orally debriefed, given a written debriefing statement, and thanked for their participation.

\section{Results}

\section{Manipulation Check}

All deliberation and implementation protocols completed by participants were inspected individually to ensure that participants understood the instructions, had chosen an appropriate project, and had completed all questionnaires. One participant in the implementation condition had written about a project for which he had not yet made a decision, and consequently his data were not included in the analyses. The remainder of the participants had completed the protocols appropriately. Those deliberating a decision typically picked such issues as whether or not to go to graduate school, whether or not to break off a relationship, and whether or not to move to another community. Those in the implementation condition typically described the steps involved in furthering a personal goal, such as completing a degree, getting a good job, getting into graduate school, becoming involved in a relationship, or changing a personal habit, such as losing weight or practicing a musical instrument.

\section{Preliminary Analyses}

Initial inspection of the means suggested gender trends, yet it was not possible to conduct Condition $\times$ Gender analyses because of the substantial gender skew in the control condition. Therefore, we conducted a multivariate analysis of variance (MANOVA) with two between-subjects variables: mindset (deliberative or implemental) and gender (male or female), and four dependent variables of mood, perceived risk, self-esteem, and dispositional optimism. We employed Wilk's criterion for the combined ratings, and the MANOVA resulted in a significant main effect for condition, $F(4,71)=12.89, p<.001$. However, the main effect for gender and the interaction between gender and condition were not significant (both $F \mathrm{~s}<1$ ). Therefore, gender was not further considered in the analyses.

\section{Dependent Measures}

We performed a one-way (deliberative, implemental, control) MANOVA on the four dependent measures of mood, perceived risk, self-esteem, and dispositional optimism. The use of Wilks' criterion for the combined ratings resulted in a significant main effect, $F(8,186)=7.42, p<.001$. Mean ratings corresponding to the subsequent univariate analyses are presented in Table 1 .

Analysis of the mood scale indicated that participants in the deliberative mindset experienced significantly poorer mood than those in the control condition and in the implementation condition, $F(2,97)=27.80, p<.0001$. Tukey HSD post hoc comparisons revealed that the deliberative mindset mean was significantly different from the control and implemental mindset means, which were not different from each other.

We had predicted that people in an implemental mindset see themselves as less susceptible to unfortunate events than those in a deliberative mindset. This prediction was strongly supported, $F(2,97)=4.69, p<.02$. Specifically, Tukey HSD post hoc comparisons revealed that implemental mindset participants saw others to be at significantly greater risk for negative events than themselves, relative to the control group and to those in a deliberative mindset. It should be noted that if participants showed no systematic capacity to distort their vulnerability to risk, one would have expected the means of all three groups to be 0 . The fact that the deliberative mindset condition mean is 6.00 means that, even in this condition, participants held a moderately high degree of perceived relative invulnerability to risk. This suggests that, although deliberative mindset and control participants are somewhat less unrealistically optimistic about their risk than implemental mindset participants, they still perceive their risk to be less than that of the average college student.

We had included self-esteem in Study 1 to see if participants in the deliberative mindset condition experienced lower self-esteem than those in the control or implemental mindset conditions. This prediction also was supported, $F(2,97)=4.72, p<$ .02. Tukey HSD post hoc comparisons revealed that participants in the deliberative mindset condition experienced poorer self-esteem than did participants in the control condition and in the implemental mindset condition.

On the grounds that deliberation forces people to be more realistic in assessing the likelihood of future events, we predicted that deliberative mindset participants would score lower on a measure of dispositional optimism, the LOT, than participants in the implemental mindset condition. Although there was a trend in this direction, $F(2,97)=2.50, p<.09$, the results were not significant.

Table 1

Impact of Mindset on Mood, Self-Esteem, Risk Perceptions, and Optimism: Study 1

\begin{tabular}{lccc}
\hline & \multicolumn{3}{c}{ Mindset condition } \\
\cline { 2 - 4 } Measure & Deliberative & Control & Implemental \\
\hline Mood & $-2.52_{\mathrm{a}}$ & $10.05_{\mathrm{b}}$ & $11.30_{\mathrm{b}}$ \\
Risk & $6.00_{\mathrm{a}}$ & $6.05_{\mathrm{a}}$ & $9.71_{\mathrm{b}}$ \\
Self-esteem & $37.55_{\mathrm{a}}$ & $41.77_{\mathrm{b}}$ & $41.08_{\mathrm{b}}$ \\
Optimism & 27.36 & 30.55 & 29.03 \\
\hline
\end{tabular}

Note. Means within rows not sharing a common subscript are signifcantly different from each other. 


\section{Mediational Analyses}

Mood has been conceptualized as a potential mediator of the impact of life experience on positive illusions and of the impact of positive illusions on subjective well-being (Taylor \& Brown, 1988). Because of the impact of mindset on mood, we investigated its potential role as a mediator between mindset and the indicators of positive illusions, namely, relative invulnerability to risk and self-esteem. In these analyses, we included only the conditions in which mindset had been experimentally manipulated (deliberative, implemental). On the risk measure, covarying out mood leaves the mindset effect largely intact, $F(1,75)=$ $5.11, p<.03$. These results are inconsistent with the idea that the reduction in perceived invulnerability to risk observed in the deliberative mindset condition is due to mood changes. Rather, the mindset manipulation may have had a direct effect in bringing about more realistic conceptions of personal risk. In contrast, mood may have somewhat mediated the impact of mindset on self-esteem. When mood is covaried out of the relationship between mindset and self-esteem, the effect is considerably reduced, $F(1,76)=2.19, p<.14 .^{3}$

\section{Discussion}

Participants in a deliberative frame of mind had significantly poorer mood, significantly lower self-esteem, and significantly lower perceived invulnerability to risk than participants in whom an implemental mindset had been induced. The results provide support for the contention that deliberation may be a time when people are relatively realistic about their talents and shortcomings and the resources and limitations of the environment. Deliberating a decision evenhandedly diminished mood and self-esteem, relative to the implemental condition and the control group. Compared with implementation participants but not the control group, deliberating participants also saw themselves as more vulnerable to risk. It should be noted, however, that deliberation did not altogether eliminate perceived invulnerability to risk. Even after deliberation, participants still believed themselves to be less at risk than the average college student of their gender for a variety of negative events in the future. Implementation participants did not differ significantly from control group participants on mood or self-esteem but showed significantly greater perceptions of invulnerability to risk. The implication is that the process of implementing a goal may especially blind people to risk but need not necessarily augment self-esteem or mood. There are difficulties with this interpretation, however, because of the skewed gender imbalance in the control group.

The role of mood in these effects is equivocal at present. Although mood was influenced strongly by the mindset manipulation, its mediational role appears to be modest, if it exists at all. It does not appear that mindset affects mood, which, in turn, damps down illusions in the deliberative condition and augments them somewhat in the implementational condition. Rather, mindset may well have a direct impact on psychological assessments of one's vulnerability to risk and, to a lesser extent, on one's impressions of oneself.

The effects of mindset on the LOT were weaker, a point that is consistent with its conceptualization as a dispositional measure of optimism. Apparently, optimistic and pessimistic dispo- sitional expectations are fairly strong and resistant to change. However, the optimism measure was presented last in the series of four measures. Inspection of Table 1 reveals that the magnitude of effects declined across the four measures. This suggests that the effects of mindset may have been wearing off over the course of the dependent measures, exerting their strongest impact on the first measure-namely, mood-and their weakest on the last measure-namely, dispositional optimism.

There are some limitations of Study 1 that complicate interpretation of the results. The first is the just-noted fact that the dependent measures occurred in a single order, which makes the results subject to alternative interpretations. Consequently, randomizing the order of dependent measures in the future is important. A second interpretational problem arises with respect to the potential mediational role of mood. The results of Study 1 were inconclusive. Because self-esteem is a dispositional and relatively stable quality, the temporary impact of mindset may have been largely accounted for by the warm glow of positive mood in the implemental condition and the chill of negative mood in the deliberative condition. On the measure of perceived invulnerability to risk, which is not a dispositional measure, mindset appears to have exerted a direct effect independent of its effect on mood. Third, although the effects of mindset on positive illusions have now been demonstrated for an illusion of control (Gollwitzer \& Kinney, 1989), for self-esteem, and for relative invulnerability to risk, additional evidence for the reliability of the effects of mindset on positive illusions would be provided by use of a broader array of tasks. Finally, because of the gender skew in the control group of Study 1, an important issue was obscured: Are participants in whom no mindset has been induced midway between participants who deliberate or plan to implement a personal project, or do their self-perceptions and assessments of vulnerability to risk look more like those of deliberators or implementers?

Consequently, in Study 2, male and female college student participants were again exposed to either a deliberative mindset manipulation, an implemental mindset manipulation, or a nomindset control condition, following the procedures of Gollwitzer and Kinney (1989). Participants then completed several dependent measures in different orders: a mood measure identical to the measure used in Study 1; a self-attribute rating scale in which they rated themselves on a variety of positive and negative qualities in comparison to the "average college student of your age and gender;" and measures of relative invulnerability to risks perceived as controllable or as uncontrollable. The decision to examine controllable and uncontrollable risks separately stemmed from our hypotheses about the nature of the implemental mindset. Specifically, participants who are implementing decisions appear to see themselves as in control of their actions and what goes on around them (cf. Gollwitzer \& Kinney, 1989). Thus, although they may regard themselves as generally quite immune to the random effects of the environment, they may see themselves as especially invulnerable to controllable risks, because they believe that, as effective actors, they can

\footnotetext{
${ }^{3}$ We also covaried out self-esteem from the mindset-personal risk relation to see if self-esteem differences created by the mindset manipulation could be regarded as a potential mediator of the effects of mindset on risk perception. Covarying out self-esteem left the mindset effect on the risk measure largely intact, $F(1,75)=8.32, p<.005$.
} 
take actions to offset any such risks that might arise. This reasoning leads to the hypotheses that implemental mindset participants will see themselves as significantly less vulnerable to risk than deliberative mindset and control participants and that this effect will be more pronounced for controllable than for uncontrollable risks. Following the logic of Study 1, we also predicted that participants who were deliberating a personal decision would have poorer mood and poorer self-perceptions as compared with control participants not exposed to a mindset manipulation, who, in turn, should have poorer mood and poorer self-perceptions than participants in the implemental mindset condition.

\section{Study 2}

\section{Method}

\section{Pretesting}

A measure was developed to assess perceptions of vulnerability to controllable and uncontrollable risks through pretesting. Specifically, 30 undergraduates in a classroom situation rated each of 20 risks (e.g., contracting a sexually transmitted disease, developing cancer) in terms of how controllable it was. Specifically, participants were told

All of us are exposed to certain risks in our lives. In some cases, we can control whether or not we encounter a particular negative event, whereas in other cases, the negative event just happens to us, that is, it is uncontrollable. For example, most people feel that they can control to a large degree whether or not they graduate from college, but most people do not think they can control whether or not they are hit by lightning during a storm. Please rate each of the risks below in terms of how controllable or uncontrollable you perceive that risk to be, on a seven-point scale ranging from "not at all controllable" to "completely controllable."

Participants then rated each of the 20 risks on the 7-point scale.

On the basis of these ratings, we selected for the main study four risks consistently perceived by participants to be controllable and four risks considered by participants to be consistently uncontrollable. The controllable risks were: addiction to prescription drugs, divorce, having a drinking problem, and being mugged. The uncontrollable risks were: developing heart disease, losing a partner to an early death, losing a limb, and developing diabetes.

\section{Participants}

Seventy participants ( 36 men and 34 women) were recruited individually by student experimenters in a research methods course. All were between the ages of 19 and 27, with a median age of 21 . All but 3 were college students. An additional 31 participants, who constituted the control condition, completed the dependent measures in a classroom situation. ${ }^{1}$ All were college students. The age range was 19 to 25 , with 12 men and 19 women.

\section{Procedure}

The procedure for Study 2 was identical to that of Study 1, with the exception of the dependent measures used.

\section{Dependent Measures}

All participants received a packet consisting of three questionnaires. The order of these questionnaires was systematically varied so that each questionnaire appeared in each of the three possible positions (first, sec- ond, third). The measure of mood was the same as that used in Study 1. A second measure assessed participants' perceived vulnerability to the controllable and uncontrollable risks noted above. Specifically, on separate 7-point scales ranging from 1 (not at all likely) to 7 (very likely), participants rated how likely it was that they or the average college student of their age and gender would encounter each of the eight risks during their lifetime. Two separate measures of perceived risk were calculated, one for the four uncontrollable risks and one for the four controllable risks. For each set of risks, a measure of perceived invulnerability was derived by subtracting the total of how the participants rated themselves across the four risks from the total of how participants rated the average college student of their age and gender. Higher scores reflect greater perceived invulnerability to risk.

A third questionnaire assessed participants' self-perceptions. Participants rated themselves in comparison to the average college student of their age and gender on a series of 21 qualities and skills (e.g., cheerfulness, academic ability) on a scale that ranged from 1 (much worse) to 7 (much better) than the average college student of their age and gender. After reverse coding the negatively worded items, we calculated the measure of self-perception by summing the self-ratings to yield a total score. Thus, if participants saw themselves as equally capable and talented as the average college student of their age and gender, their total score would be $84 .^{4}$

After participants completed the packet of four dependent measures, their reactions to the study were ascertained. They were probed for suspicion, and they were carefully debriefed.

\section{Results}

\section{Manipulation Check}

All participants' responses to the deliberative and implemental exercises were examined to ensure that participants understood and had complied with the instructions and materials. One implementation participant failed to comply with the instructions, because his responses indicated that he was clearly deliberating a decision. Consequently, his data were not included. All other participants completed the materials correctly. The kinds of personal goals deliberated and implemented in Study 2 were very similar to those identified by participants in Study $1 .^{5}$

\section{Preliminary Analyses}

Preliminary analyses examined the effects of order of questionnaire and gender. Because clear effects for gender emerged in some of the analyses, and trends emerged in the others, gender was retained as a variable in all subsequent analyses. Order of

\footnotetext{
${ }^{4}$ The items were athletic ability, cheerfulness, leadership ability, social self-confidence, popularity with own sex, popularity with opposite sex, writing ability, public speaking ability, intellectual self-confidence, originality, creativity, academic ability, drive to achieve, artistic ability, sensitivity to others, understanding of others, clarity of personal goals, confidence in the ability to obtain personal goals, personal appearance, self-respect, and individuality.

${ }^{5}$ As these decisions and goals imply, most of the participants in both Studies 1 and 2 were seniors who were at the time involved in either important decisions or the implementation of important goals, or both. Earlier pilot studies with college student freshmen and sophomores revealed that the mindset manipulation effects were weaker, apparently because many freshmen and sophomores were not weighing important decisions and implementing important courses of action other than those routinely involved in the pursuit of their studies.
} 
the questionnaires in the dependent measure packet, however, produced no significant effects. Thus, there was no indication that effects were stronger on variables completed immediately following the mindset manipulation relative to those completed a few minutes later. Consequently, order of questionnaire completed was not retained as a variable in subsequent analyses.

\section{Primary Analyses}

Data were analyzed by means of a two-way MANOVA with mindset (deliberative, implemental, control) and gender (male or female) as the two independent variables and mood, self-perceptions, uncontrollable risks, and controllable risks as the four dependent measures. The use of Wilk's criterion for the combined ratings resulted in a significant main effect for mindset, $F(8,182)=15.10, p<.001$, a significant effect for gender, $F(4$, $91)=2.94, p<.03$, and no significant interaction $(F<1)$. Mean ratings corresponding to the subsequent univariate analyses are presented in Table 2.

In terms of mood, on the basis of Taylor and Brown's (1988) theorizing and the results of Study 1, we expected that implementation participants would show the most positive mood, followed by control participants, with deliberative participants showing the poorest mood. This hypothesis was strongly supported, $F(2,94)=38.07, p<.001$. Tukey HSD post hoc comparisons indicated that each of the marginal means for condition was significantly different from the others. That is, implementation participants' mood was significantly higher than that of control participants, which was in turn significantly higher than that of deliberation participants. There was no significant effect for gender and no interaction between condition and gender.

In terms of self-perceptions, we hypothesized that participants in the implementation condition would see themselves more positively than those in the control condition, who would in turn see themselves more positively than participants in the deliberation condition. This hypothesis was also strongly supported, $F(2,94)=16.02, p<.001$. Post hoc tests revealed that implementation participants held significantly more positive self-perceptions than control participants, who in turn held significantly more positive perceptions than participants in the deliberative mindset condition. In addition, there was a significant gender effect, $F(1,94)=9.34, p<.003$. Female participants' self-perceptions were significantly poorer than those of men. There was also a marginally significant interaction between gen-

Table 2

Impact of Mindset on Mood, Self-Perceptions, and Uncontrollable and Controllable Risk: Study 2

\begin{tabular}{lccc}
\hline & \multicolumn{3}{c}{ Mindset condition } \\
\cline { 2 - 4 } \multicolumn{1}{c}{ Measure } & Deliberative & Control & Implemental \\
\hline Mood & $-1.85_{\mathrm{a}}$ & $3.94_{\mathrm{b}}$ & $11.37_{\mathrm{c}}$ \\
Self-perceptions & $95.91_{\mathrm{a}}$ & $102.90_{\mathrm{b}}$ & $111.89_{\mathrm{c}}$ \\
Uncontrollable risk & $2.35_{\mathrm{a}}$ & $2.97_{\mathrm{a}}$ & $5.03_{\mathrm{c}}$ \\
Controllable risk & $3.4 \mathrm{I}_{\mathrm{b}}$ & $3.10_{\mathrm{b}}$ & $8.26_{\mathrm{d}}$ \\
\hline
\end{tabular}

Note. Means within rows and columns not sharing a common subscript are significantly different from each other. der and condition, $F(1,94)=2.50, p<.09$; male participants in the control and deliberative conditions saw themselves as ap. proximately equivalently talented and skilled, whereas women in the deliberative condition regarded themselves significantly more poorly than did participants in all other conditions.

In terms of perceived invulnerability to risk, we hypothesized that participants in the implementation condition would see themselves as more invulnerable to risk than those in the control condition, who would, in turn, see themselves as more invulnerable than participants in the deliberation condition. We also predicted that these effects would be more true for controllable than uncontrollable risks. To test these hypotheses, we conducted a three-way analysis of variance (ANOVA) with mindset (deliberative, implemental, control) and gender as two between-subjects variables and type of risk (uncontrollable or controllable) as a within-subjects variable. As Table 2 indicates, these predictions were partially supported. The overall effect for condition was significant, $F(2,94)=33.29, p<.001$. Individual means comparisons indicated that for both uncontrollable and controllable risks, implemental mindset condition participants saw themselves as significantly less vulnerable to risk than participants in the deliberative and control conditions; however, participants in the deliberative and control conditions did not differ from each other. This pattern is consistent with the results of Study 1 concerning perceived risk, in which deliberative and control group participants did not differ from each other but differed significantly from participants in the implemental mindset condition. There was no effect of gender and no interaction of gender with condition. In addition, there was a significant effect for type of risk, $F(1,94)=19.42, p<.001$. All participants saw themselves as significantly more invulnerable to controllable risks than to uncontrollable risks. There was also a significant Condition $\times$ Risk interaction, $F(2,94)=7.93, p<$ .001 . The interaction is partially accounted for by the fact that, in the uncontrollable risk condition, control participants regarded themselves as slightly more invulnerable to risk than the deliberative mindset condition participants, whereas in the controllable risk condition, participants in the control group regarded themselves as slightly less invulnerable to risk than the deliberative mindset participants. Although this latter reversal is not significant $(F<1)$, it is nonetheless directionally inconsistent with the hypotheses. A more potent factor in the signifcant interaction is the fact that implemental mindset participants responded somewhat differently to uncontrollable and controllable risks. Specifically, as the means comparisons in $\mathrm{Ta}$ ble 2 indicate, participants in the implemental mindset condition saw themselves as especially invulnerable to controllable risks, compared with participants in the control group and the deliberative condition. Thus, the hypotheses that participants in an implemental frame of mind would see themselves as more invulnerable to risks, especially controllable ones, compared with deliberating and control participants, were supported.

\section{Mediational Analyses}

As in Study 1, we investigated the potential role of mood as a mediator between mindset and the indicators of positive illusions, namely, invulnerability to controllable and uncontrollable risks, and self-perceptions. The results suggest no mediational role for mood. The self-perception effect remains largely 
intact when mood is covaried out, $F(2,96)=5.29, p<.007$. Similarly, the effects of mindset on uncontrollable risks, $F(2$, $96)=3.95, p<.03$, and on controllable risks, $F(2,96)=19.08$, $p<.001$, are still strong. Thus, Study 2 suggests that mood does not mediate the effect of mindset on self-perception or perceived vulnerability to risk.

\section{Discussion}

Consistent with our theoretical analysis relating the dynamics of mindset to positive illusions and with the evidence of Gollwitzer and Kinney (1989) and from Study 1, the results of Study 2 clearly indicate that perceptions indicative of positive illusions are more realistic following the induction of a deliberative mindset and more exaggerated following the induction of an implemental mindset. These results expand the findings of Gollwitzer and Kinney beyond their illusion-of-control data and enlarge on the effects of Study 1 by demonstrating that perceptions of one's skills and talents may be affected by the temporary induction of a deliberative or implemental mindset. In addition, there is evidence that perceptions of one's vulnerability to both controllable and uncontrollable risks are affected by mindset, with implemental participants seeing themselves as significantly less vulnerable to both types of risks than control participants or deliberative mindset participants. These data support the interpretation that implementation makes potential risks somewhat less accessible than is otherwise the case. Yet it is important to reiterate that even participants in the deliberative mindset condition and the control group showed self-perceptions and perceptions of invulnerability to controllable and uncontrollable risk that exceeded the self-perceptions and invulnerability to risk ascribed to other college students of their age and gender. Thus, although positive illusions appear to fade in response to conditions that foster deliberation, they do not disappear altogether.

There were clear gender differences in self-perception in Study 2. Specifically, women held significantly poorer self-perceptions, especially in the deliberative mindset condition. The experimenters who had debriefed participants offered two potential explanations for this effect on the basis of their conversations with participants. First, several female participants spontaneously mentioned that they had come to the end of their senior year, and they were no closer to having resolved or completed any of their major life tasks (choosing a career, getting married, having children) than they had been 4 years earlier when they began college. This may account for a sense of discouragement that emerged especially when they were deliberating their personal decisions. A second possibility spontaneously voiced by several of the female participants was the pessimism they felt as young women facing a poor job market characterized by gender discrimination, a pessimism that may have been enhanced by deliberating life decisions. A third explanation draws on recent findings that women's style of responding to depressive prospects and moods is more ruminative than that of men (for a review, see Nolen-Hoeksema, 1993). It seems possible, then, that women in the present study more readily embraced the deliberative mindset instructions that encourage rumination and thus developed a stronger deliberative mindset than men. Whether any of these, a combination of these, or any other explanation characterized the poorer self-perception of the female participants, particularly in the deliberative mindset condition is, however, not clear.

The relative gender balance of Study 2 makes it possible to interpret the magnitude of the control group means relative to the deliberative and implemental mindset group means. Specifically, on two measures (mood and self-perceptions), the control group fell roughly midway between the deliberative and implemental mindset groups. This pattern suggests that deliberation reduces mood and self-perceptions, and implementation enhances mood and self-perceptions, relative to individuals who are not explicitly deliberating or planning to implement a decision. However, the pattern of perceptions of vulnerability to controllable and uncontrollable risks is different. Specifically, deliberative and control group participants saw themselves as modestly less vulnerable to both uncontrollable and controllable risks than the average college student. Although both groups saw themselves as more vulnerable to uncontrollable than controllable risks, within each risk condition, the deliberative and control group participants were not significantly different from each other. In contrast, participants in the implemental mindset condition saw themselves as substantially less vulnerable to uncontrollable, and especially to controllable, risks. The implications of these different patterns is that deliberation may not particularly increase perceived vulnerability to risk, but implementation may especially blind people to risk. Such perceptions may be adaptive in helping people to further the goals they have chosen to implement by keeping them from being sidetracked or concerned about potential risks. The fact that controllable risks are especially affected implies that implementation enhances feelings of personal control (Gollwitzer \& Kinney, 1989) with respect to the ability to avoid risky circumstances.

Analyses of the effects of mindset on mood and the mediational analyses that followed suggest little mediational role for mood in these effects. Specifically, although mindset clearly had an impact on mood, with deliberative participants in a signifcantly poorer mood than participants in the implementation or control conditions, these mood changes bore little relation to effects on the self-perception or risk measures.

Studies 1 and 2 suggest that participants in a deliberative mindset are less vulnerable to positive illusions than are participants in an implemental frame of mind. However, two important questions remain, both of which pertain to the generalizability of the results. The first issue is whether people spontaneously deliberate an unresolved personal problem in ways analogous to Gollwitzer and Kinney's (1989) deliberative mindset manipulation that would, in turn, lead them to be more realistic in their perceptions. If people's spontaneous deliberations are not marked by an evenhanded consideration of both sides of an issue, self-made deliberations cannot be assumed to provide a window of realism.

The second issue pertains to the question of how accessible this window of realism is. More specifically, people who turn an unresolved problem into an intended project by making a decision may close their minds to this window, as postdecisional individuals do not possess easy access to impartial deliberative thinking. The action phases and mindset notion (Gollwitzer, 1990,1991 ) holds that, in the postdecisional phase, people are facing a different type of task than in the predecisional phase. Whereas predecisional people try to solve the task of choosing goals that are feasible and desirable, at the postdecisional phase, 
people attempt to implement the chosen goals (intended projects) as efficiently as possible. By becoming involved with these different types of tasks, people are expected to develop distinct cognitive orientations or mindsets that help solve the respective task at hand. Indeed, postdecisional individuals have been found to be more effective in processing information on how to implement goals as compared with information on desirability (pros and cons, i.e., positive and negative expected values) and feasibility (positive and negative expectations; see Gollwitzer et al., 1990; Heckhausen \& Gollwitzer, 1987).

Moreover, the action phases and the mindset notion (Gollwitzer, 1990, 1991) holds that the move from the predecisional phase to the postdecisional phase is based on committing oneself to implement the chosen goal. The noncommittal, potential goals deliberated in the predecisional phase become binding goal commitments in the postdecisional phase. Thus, the vacillation of the predecisional phase is replaced by determination in the postdecisional phase. This determination directed to the implementation of the chosen goal should reduce a person's motivation to start deliberating the goal's pros and cons anew, as this would again induce predecisional vacillation. Accordingly, if thinking about the goal's expected value is triggered in the postdecisional phase (e.g., through verbal instructions), postdecisional individuals should avoid evenhanded deliberation. This can be achieved by conducting a partial analysis of pros and cons that focuses primarily on the pros, as this does not undermine one's determination but rather reinforces it.

Accordingly, we hypothesized that instructions that trigger spontaneous evenhanded deliberation with predecisional people fail to do so with postdecisional people, because these individuals (a) primarily think about implementation-related issues and (b) take sides with the chosen goal in the sense of emphasizing the positive consequences (pros) of goal achievement while downplaying the negative consequences (cons). Theorists in the tradition of dissonance theory (e.g., Jones \& Gerard, 1967; Kiesler, 1971; Wicklund \& Brehm, 1976) claimed that irrevocable commitments originate when people actually act on their goals. Therefore, our experimental design included two postdecisional groups: one group that had not yet started to act on its goals, and one that was already on its way. This way, we could test whether the window of realism (i.e., evenhanded deliberation) is closed for both postdecisional groups or only for postdecisional people who have already started to implement their goals.

\section{Study 3}

In Study 3 we tested these ideas by asking one group of participants (predecisional group) to name an unresolved personal issue of the "Should I do $X$ or not?" type (see deliberative mindset condition of Studies 1 and 2) and then to freely think about the decisional issue at hand, trying to decide whether to choose $X$ or not. Immediately after participants had terminated deliberation, they were asked to report on their thoughts in as much detail as possible. A second group of participants (first postdecisional group) was asked to name an intended project, as was done in the implemental mindset condition of Studies 1 and 2; these participants were then asked to reflect on the project and to determine whether they should or should not have chosen it. The third group of participants (second postdecisional group) was given the same instructions with regard to thinking about the intended project; however, they were asked to do so for an intended project on which they had gotten started (i.e., executed at least one implementational step) but which they had not yet completed. This second postdecisional group was included to determine if only those people who are already "on their way" find it difficult to deliberate their choice of project in an evenhanded way and if postdecisional participants who have not yet gotten started are still in a position to do so.

\section{Method}

\section{Participants}

Eighty male students at the University of Munich were recruited. Up to 5 participants at a time attended each session. The sessions were conducted in a medium-sized lecture hall. Participants were randomly assigned to conditions and seated at tables separated by screens so that they could not see each other. On each table, the female experimenter had placed a stack of envelopes. Participants were told that these envelopes would contain the written instructions and the test materials. They should start with the top envelope and work their way through the stack, following their own pace.

\section{Procedure}

The first envelope contained general instructions to orient students toward the experiment. Participants were told that the study was designed to analyze the psychological processes that guide a person's choice of goals and their implementation. The instructions in the second envelope differed for the three conditions of the experiment: the predecisional participants, and two groups of postdecisional participants, Group A and Group B.

Predecisional participants were asked to indicate an unresolved personal problem of the "Should I do $X$ or not?" type, whereas the postdecisional participants in Group A were requested to name an intended project. The instructions used were the same as those as in Studies 1 and 2 for the deliberative mindset condition and the implemental mindset condition, respectively. Participants in the second postdecisional group (Group B) received the same instructions as the first postdecisional group but were requested to indicate only intended projects on which they had already gotten started (i.e., at least one implemental step had been taken) but were still trying to complete (i.e., at least one implemental step was still missing).

After participants had named their personal problems or intended projects, they received written instructions on how to reflect on them. The instructions for predecisional participants read as follows:

You are kindly requested to deliberate, in your own personal manner, the unresolved issue you have named. Please note (1) that you can spend as much time doing this as you personally find appropriate, (2) that you approach the decision issue as you usually do when you decide whether you should do $X$ or not, and (3) that you terminate your efforts when you feel that additional thought would not achieve further clarity. Now please lean back and think about your decision issue. Once you have terminated deliberation, please turn to the next envelope on your desk and complete the questionnaire it contains.

The final envelope contained a self-report sheet that helped participants come up with a veridical introspection on their thoughts (see below).

Instructions for the postdecisional groups were different in that they referred to a decision already made:

When you think of your project, do you feel that you made the 
right choice? Or should you have refrained from choosing this project? You are kindly requested to deliberate, in your own personal manner, the project you have named. Please note (1) that you can spend as much time doing this as you personally find appropriate, (2) that you approach the project as you usually do when you want to decide whether you should or should not have chosen it, and (3) that you terminate your efforts when you feel that additional thought would not achieve further clarity. Now please lean back ... [same as above].

\section{Dependent Measure}

The final envelope contained a self-report sheet that was designed to probe into participants' experienced thoughts. The format of this sheet has been successfully used before (e.g., Heckhausen \& Gollwitzer, 1987). Participants first had to report their most recent thoughts, that is, thoughts experienced just before terminating deliberation. Then, they were told to list the second-most recent thoughts, and thereafter, the first thoughts that came to mind when starting deliberation. Finally, participants had to write down everything they had thought of in between.

This type of verbal protocol was used because it helps participants correctly recall their experienced thoughts, which is important for obtaining veridical self-reports on the flow of thought (Ericsson \& Simon, 1980). Because the last thoughts experienced are reported first, participants can read them off from short-term memory. In addition, these thoughts should facilitate the retrieval of other connected thoughts, which are stored by episodic association in long-term memory. Moreover, having participants report on the thoughts experienced at the starting point of deliberation provides participants with a powerful retrieval cue.

\section{Results}

\section{Named Projects}

We classified unresolved personal issues (predecisional participants) and intended projects (Groups A and B) according to three categories: career related (e.g., studying abroad), lifestyle related (e.g., buy a fashionable watch), or interpersonal (e.g., get together with an old friend). Career-related themes were the most frequent $(63 \%)$, followed by lifestyle-related (25\%) and interpersonal $(13 \%)$ themes. A chi-square analysis revealed that these different themes were distributed about equally across the three groups of participants, $\chi^{2}(4, N=80)=3.36, p=.50$.

\section{Scoring of Reported Thoughts}

In a first step, participants' reports were analyzed in terms of the number of distinct thoughts listed. The marked thoughts were then classified into the following categories by two independent raters: a) positive or negative consequences (i.e., thoughts on the desirability of choosing/having chosen $X$ ), b) positive or negative expectancies (i.e., thoughts about the feasibility of $X$ ), c) meta-deliberative issues (i.e., self-instructions aimed at effective deliberation, such as "Let's think about this carefully!"), d) implementational issues (i.e., thoughts on when, where, and how to achieve $X$ ), e) meta-implementational issues (i.e., self-instructions aimed at achieving $X$, such as "Don't get discouraged by setbacks!"), and f) task-irrelevant issues (i.e., thoughts on themes irrelevant to the task at hand, such as "I like the experimenter!').

This coding scheme permitted classification of all of the thoughts reported. Agreement between raters was close to perfect; the few disagreements were resolved by discussion.

\section{Frequency of Thought}

The absolute frequencies of the thoughts participants reported are listed in Table 3. Participants reported 5.84 thoughts on average; predecisional participants listed more thoughts $(M$ $=7.00)$ than postdecisional participants of both Group $\mathrm{A}(M=$ 4.96), $t(77)=2.51, p<.02$, and Group B $(M=5.52), t(77)=$ $1.90, p=.06$.

Desirability. The relative frequency of thoughts about positive and negative consequences amounted to $33 \%$. A 2 (desirability: pros vs. cons) $\times 3$ (experimental condition: predecisional, postdecisional Group A, postdecisional Group B) ANOVA on the reported thoughts about consequences revealed a significant interaction effect, $F(2,77)=4.07, p=.02$. Whereas predecisional participants thought a little more about negative as compared with positive consequences $(1.85$ vs. $1.65, n s)$, postdecisional participants reflected more on positive than negative consequences (Group $\mathrm{A}=1.20$ vs. .24 for negative and positive consequences, respectively, $\mathrm{t}[24]=3.51, p<.01$; Group $B=.62$ vs. .14 for positive and negative consequences, respectively, $\mathrm{t}[28]=2.14, p<.05$ ). In addition, thinking about consequences in general was less prevalent in postdecisional participants as compared with predecisional participants. The number of desirability-related thoughts for the predecisional participants was significantly higher than those of the postdecisional participants of Group A $(p<.01)$ which, in turn, were higher than those of the postdecisional participants of Group B $(p<.001)$; overall, $F(2,77)=10.19, p<.001$.

Feasibility. Participants of all groups reported few thoughts about feasibility-related issues (relative frequency: 6\%). A 2 (feasibility: positive vs. negative expectations) $\times 3$ (experimental condition) ANOVA did not reveal any significant effects (all $p s>.25$ ).

Meta-deliberation. Thoughts aimed at stimulating intensive deliberation of the question at hand ("Should I choose $X$ ?" or "Was I correct in choosing $X$ ?", respectively) were relatively frequent $(16 \%)$. The majority of these thoughts, however, was found with predecisional participants $(M=2.15)$. Postdecisional participants of both experimental groups engaged in less meta-deliberation: Group A $(M=0.20), t(77)=5.24, p<.001$; and Group $B(M=0.38), t(77)=4.94, p<.001$; overall $F(2$, $77)=17.24 p<.001$.

Implementation. The relative frequency of thoughts about when, where, and how to implement $X$ was rather low (13\%), but there were large differences between pre- and postdecisional participants. Predecisional participants $(M=0.38)$ reported only half as many implementation-related thoughts than postdecisional participants of both groups; Group A $(M=0.84)$, $t(77)=1.54, p<.13 ;$ Group B $(M=1.00), t(77)=2.16, p=$ .03 ; overall $F(2,77)=2.47, p=.09$.

Meta-implementation. Postdecisional participants reported thoughts designed to stimulate the implementation of $X$ (e.g., "You better move on $X$ !"). This type of thought was rarely observed with predecisional participants $(M=0.04)$. Postdecisional participants in Groups A $(M=1.16), t(77)=4.04, p<$ .001 ; and in Group B $(M=1.14), t(77)=4.10, p<.001$, reported many more such thoughts than predecisional partici- 
Table 3

Mean Numbers of Different Types of Thoughts by Pre-and Postdecisional Participants

\begin{tabular}{lccc}
\hline & \multicolumn{3}{c}{ Experimental condition } \\
\cline { 2 - 4 } \multicolumn{1}{c}{ Thought categories } & $\begin{array}{c}\text { Predecisional } \\
(n=26)\end{array}$ & $\begin{array}{c}\text { Postdecisional } \\
(\text { Group A; } n=25)\end{array}$ & $\begin{array}{c}\text { Postdecisional } \\
\text { (Group B; } n=29)\end{array}$ \\
\hline Desirability & & & 0.62 \\
$\quad$ Positive consequences (pros) & 1.65 & 1.20 & 0.14 \\
$\quad$ Negative consequences (cons) & 1.85 & 0.24 & 0.21 \\
Feasibility & & 0.16 & 0.31 \\
$\quad$ Positive expectations & 0.04 & 0.12 & 0.38 \\
$\quad$ Negative expectations & 0.27 & 0.20 & 1.00 \\
Meta-deliberation & 2.15 & 0.84 & 1.14 \\
Implementation & 0.38 & 1.16 & 1.72 \\
Meta-implementation & 0.04 & 1.04 & \\
Task-irrelevant issues & 0.65 & & \\
\hline
\end{tabular}

pants; overall $F(2,77)=10.98, p<.001$. The relative frequency of this type of thought for all participants is $13 \%$.

Task-irrelevant issues. This final category of thoughts emerged fairly frequently (19\%). The three experimental groups, however, differed significantly in how often irrelevant thoughts were reported; overall $F(2,77)=3.12, p<.05$. The most irrelevant thoughts were reported by postdecisional Group B $(M=1.72)$. Fewer were observed in postdecisional Group A $(M=1.04), t(77)=1.55, p=.12$, and even fewer in the predecisional group $(M=0.65), t(77)=2.45, p<.02$.

\section{Discussion}

Study 3 strongly suggests that people deliberate their unresolved problems (e.g., "Should I do $X$ or not?") in an evenhanded manner. The sole request to reflect on whether to make a change decision or not (i.e., do $X$ or not) triggers a deliberation that is evenhanded in terms of considering both pros and cons. As this type of deliberation was shown to create a mindset associated with more moderate self-perceptions, reduced illusion of control, and a less optimistic view of the future (Studies 1 and 2), people's spontaneous deliberations apparently provide a window of realism.

As soon as deliberation is focused on intended projects, evenhandedness no longer occurs. The thoughts reported by the postdecisional participants of Study 3 indicate a striking reluctance to engage in deliberation: First, postdecisional participants did not motivate themselves to find clarity. We observed few self-instructions aimed at motivating deliberation. Such meta-deliberative thoughts were most frequently reported by predecisional participants. Second, postdecisional participants' sluggishness to deliberate their projects was also indicated by the many irrelevant thoughts reported. Such irrelevant thoughts (e.g., "This lecture hall is nice") were reported infrequently by predecisional participants. Third, postdecisional participants reflected much less on pros and cons than did predecisional participants and, even more important, they clearly preferred to think about pros over cons. Finally, postdecisional participants tuned in on issues of implementation. They tended to think more than predecisional participants about how to implement their decisions, and they tried to motivate themselves to successfully implement the decision made (e.g., they had meta-implementational thoughts, such as "Don't get frustrated when things don't work out right away").

If one keeps in mind that postdecisional participants were explicitly instructed by the experimenter to deliberate the value of their decision, the thoughts reported by postdecisional participants can only be interpreted as a strong resistance to deliberate decisions already made. This is true for both groups of postdecisional participants, those who are still waiting to get started on implementing their decisions and those who have already gotten started. If anything, the latter seem to be even less willing to deliberate the value of their intended projects, as they showed comparatively fewer desirability-related thoughts.

It is surprising that both pre- and postdecisional participants reported so few feasibility-related thoughts. As feasibility issues are relevant to both making choices as well as implementing them, why did we find only a few thoughts on positive and negative expectations? Two answers come to mind: First, as our predecisional participants were allowed to name their own personal problems, they may have indicated only issues they were certain that they could successfully implement. In other words, they might have thought that naming their dreams would make them look foolish. Second, feasibility may become an issue for postdecisional individuals only when they are actually confronted with difficulties. This was not the case with our postdecisional participants, as they were asked to think solely about the correctness of their decisions.

\section{General Discussion}

Marcel Proust stated: "All our decisions are made in a state of mind that is not going to last." The data from three investigations bear out this observation. The results are consistent with the analysis of mindset offered by Gollwitzer $(1990,1991)$ and with Taylor and Brown's (1988) hypothesis that people experience "time-outs" from positive illusions, occasions when they are more frank and honest with themselves. Deliberating a course of action appears to be such an occasion. In contrast, implementation of a course of action appears to be a time when positive illusions are mustered, even exaggerated, in service of an explicit goal.

The present results are consistent with Gollwitzer and Kinney's (1989) findings that deliberative mindset participants 
were less vulnerable to an illusion of control than participants in an implemental mindset. The present studies go beyond those findings by demonstrating that they apply to positive illusions more generally. Deliberative and implemental mindset affects not only people's construals of unfamiliar situations but also more stable and experience-based self-perceptions and beliefs about the risks their personal futures hold. Moreover, the findings extend not only to events perceived as relatively uncontrollable but also to events perceived to be under a degree of personal control. Thus, the effects of mindset on positive illusions would appear to be extensive. Investigation of potential mediators suggests that alterations in mood, although reliably related to mindset, are unlikely to be the mediator by which mindset affects positive illusion. Finally, Study 3 provides validating evidence that the mindset manipulation corresponds to how people actually deliberate or plan to implement personal goals and projects.

The results of Study 3 clearly indicate that the window of realism afforded by deliberation is eliminated once people move to the postdecisional phase. Projects that are "on the way" as well as projects that still await implementation are no longer deliberated, even when deliberation is explicitly encouraged. Rather, postdecisional thought is marked by a consideration of the positive features of the to-be-implemented project and, as Studies 1 and 2 indicate, with a general frame of mind that fosters the positive illusions of self-aggrandizement, an illusion of control, and unrealistic optimism about controllable and uncontrollable risks. These findings, then, help provide a resolution to the paradox posed in Taylor and Brown's (1988) analysis: If normal people hold positive illusions about themselves, the world, and the future, how do they benefit from and make use of important negative feedback that comes to them from their own behavior and from other people? The answer may lie in the fact that this feedback is used to determine courses of action at choice points, but awareness of and implications of the feedback may dim, once a course of action has been selected and is being or about to be implemented.

Taking a functional perspective, the psychological consequences of deliberative and implemental mindsets would seem to be highly adaptive. Making decisions about one's life course is an important task and often determines what one will be doing for years or even a lifetime. Many of the participants deliberating in this study, for example, were debating whether or not to go to graduate school, or which graduate program to enter, decisions likely to profoundly influence their occupational history for the rest of their lives. Similarly, several of the participants were debating whether or not to marry a particular partner, another decision with potentially lifelong implications. Relatively realistic thinking would seem to be highly functional when it comes to making decisions about such wishes, because such decisions deeply affect a person's day-to-day conduct as well as long-term strivings and aspirations. If positive illusions were in ascendance during deliberations, they could lead to decisions that are prone to frustration: People could commit themselves to pursuits that turn out much more negatively than anticipated. Thus, if such decisions are made in a relatively unbiased frame of mind, presumably better decisions are made than if positive illusions run rampant, leading people to premature closure or to decisions that ignore important negative feedback.
On the other hand, once a decision has been made and the task is to implement the selected goal, positive illusions may be adaptive. Somewhat distorting one's resources, one's chances for success, and the beneficence of the environment may enable people to strive longer and harder to reach their goals, thus bringing about a self-fulfilling prophecy (Taylor \& Brown, 1988). Moreover, unbroken persistence is vital if implementation is to be successful, especially in the face of hindrances and barriers. It is not surprising, then, that people who are in the process of implementing an intended project do not reflect on its value in an evenhanded manner. Such deliberation would undermine their illusions and, thus, hinder efficient goal achievement.

There is at least one potential confound in the manipulation of mindset that needs to be addressed. It may be that the kinds of projects deliberated by participants differ fundamentally from the projects implementation participants selected, and that the differences observed on positive illusions can be accounted for by project differences rather than mindset differences. Thus, for example, deliberative problems may be more complicated, less desirable, or less feasible, which may be precisely why they are still being deliberated rather than implemented. Accordingly, we selected a random sample of 20 deliberation problems and 20 implementation goals and had them rated by two coders who were unaware of which condition (deliberative or implemental) was the source of the topic. Coders rated the problems or goals as to their simplicity-complexity, desirability-undesirability, and feasibility-infeasibility on 10point scales with labeled endpoints. There were no differences on any of the ratings as a function of whether the problem/goal was one being deliberated or one being implemented. ${ }^{6}$ Although this analysis does not entirely rule out the possibility that deliberative mindset participants are contemplating fundamentally different problems than implementation participants, ${ }^{7}$ it provides some reassurance that topics were roughly comparable between the two conditions, at least in terms of these dimensions.

The question, nonetheless, remains: What exactly is manipulated by the mindset manipulation that affects people's positive illusions? One could argue that by putting people in a state of prolonged indecision, the deliberative mindset changes their perceptions of themselves which, in turn, accounts for the effect of the manipulation on positive illusions. Deliberation may, for example, lower self-esteem which, in turn, affects other self-perceptions and judgments of control. Study 1 provided an opportunity to examine the mediational role of self-esteem in accounting for the effect of mindset on risk perceptions, but there was no indication in that analysis that self-esteem mediated those effects. This does not, however, altogether rule out the pos-

\footnotetext{
${ }^{6}$ The simplicity-complexity means were: deliberative $=5.68$, implemental $=5.05(\mathrm{t}[38]=1.03)$. The desirability-undesirability ratings were: deliberative $=4.03$, implemental $=3.95(\mathrm{t}[38]<1)$. The feasibility-infeasibility ratings were: deliberative $=3.55$, implemental $=3.58$ $(\mathrm{t}[38]<1)$.

${ }^{7}$ For example, it is possible that the deliberation version of a problem ("Move to San Jose?") is psychologically more complex, undesirable, or infeasible than the implementation version of the problem ("Move to San Jose") in ways not captured by the simple descriptions provided by participants.
} 
sibility that some involvement of the self is central to the effects of the mindset manipulations.

Gollwitzer and Kinney (1989) suggested another possible mediating mechanism of mindset. The implemental mindset manipulation is expected to create a strong sense of determination to implement the project or goal at hand. This determination transfers to subsequent situational contexts. Accordingly, implemental mindset participants should no longer try to find out whether they can or cannot control the target light in a contingency learning task but should set themselves the goal to control it. Supporting these ideas, a positive correlation between participants' strength or determination or obligation to implement their project and the reported illusion of control was observed in Gollwitzer and Kinney's (1989) study. In the present study, the determination to implement one's project may simply have transferred to participants' risk perceptions. Implemental participants felt compelled to control these risks and therefore experienced more control over them. Similarly, implemental mindset participants' determination to achieve their projects may also have guided their self-perceptions when answering questions on their personal strengths (e.g., high academic ability, originality, creativity, etc.). People who feel obligated to achieve an important project can no longer conceive of themselves as characterized by weaknesses. The deliberative mindset manipulation, on the other hand, should undermine feelings of determination. Rather, a critical attitude is induced because analyzing the question of whether one should pursue a certain goal or not demands careful scrutiny of its desirability (i.e., "What are the pros and cons?") and feasibility (i.e., "Am I in a position to implement it?"). If this critical attitude is transferred to judging the controllability of risks, illusions of control cannot develop. Similarly, ascribing overly positive personal attributes (e.g., high ability) comes into direct conflict with this critical attitude. Supporting this line of thought, Gollwitzer and Kinney (1989) observed that the more intensively deliberative participants pondered their unresolved personal problems, the less pronounced were their illusions of control.

The results of Studies 1 and 2 imply that mindset effects have some stability over time and generalize across situations. Remember that the order of the dependent variables did not play a role, and the dependent measures did not match in content, the issues people tackled when working on the mental exercises that led to the deliberative or implemental mindset, namely, unresolved personal issues or intended projects, respectively. Accordingly, once the deliberation of a specific unresolved personal issue has opened the window of realism by inducing a deliberative mindset, this window will stay open for awhile, not just for the reflection of the problem at hand but for other issues as well. The illusory optimism triggered by planning the implementation of a specific intended project should also persist for some time and transfer to other tasks. One important implication is that people can deliberately control their degree of realism and optimism of their information processing at large. By addressing a specific issue in a deliberative or implemental manner, respectively, they end up with generally more realistic or illusory views of themselves, their control, and their future.

Future research might profitably be directed to two areas. First, are there other, as-yet-unidentified characteristics of thought that are differentially altered by deliberating versus implementing a goal-related action sequence? We have identified the illusion of control (Gollwitzer \& Kinney, 1989), mood, selfaggrandizement, and unrealistic optimism about future controllable and uncontrollable risks as four areas, but there may be other cognitions that would similarly differ. For example, people may overestimate the affordances of the environment, the likelihood that other people will help them, and the likelihood that certain resources will be plentiful or available during implementation relative to deliberation. Implementation may also induce a form of tunnel vision, such that people think about their likely success and likely timetable of completion without reference to impediments that are likely to arise, or other aspects of their life that will engage their time and other resources as well (cf. Buehler, Griffin, \& Ross, 1994). Thus, for example, professors who estimate that they can complete a project in 2 months may ignore the fact that there are other deadlines to meet, teaching obligations, and family members whose needs must be addressed as well during this time period.

A second direction in which research might profitably move is toward identifying whether there are other conditions under which positive illusions are reduced that provide the same realistic window that goal deliberation apparently affords. There is some evidence, for example, that illness enhances people's subjective vulnerability to a wide variety of threatening events (Kulik \& Mahler, 1987) and, thus, being sick may be a time when people have an opportunity to reflect relatively realistically on their talents, aspirations, decisions, and goals. Similarly, because depression is thought to be associated with more realistic or more pessimistic perceptions of oneself, the world, and the future (e.g., Alloy \& Abramson, 1979), it may be that intermittent bouts of sadness, frustration, poor mood, loss experiences, or stress may induce similar windows of realism. Subsequent research can address these and related possibilities.

\section{References}

Alloy, L. B., \& Abramson, L. Y. (1979). Judgment of contingency in depressed and nondepressed students: Sadder but wiser? Journal of Experimental Psychology: General, 108, 449-485.

Aspinwall, L. G., \& Taylor, S. E. (1992). Modeling cognitive adaptation: A longitudinal investigation of the impact of individual differences and coping on college adjustment and performance. Journal of Personality and Social Psychology, 63, 989-1003.

Aspinwall, L. G., \& Taylor, S. E. (1993). The effects of social comparison direction, threat, and self-esteem on affect, self-evaluation, and expected success. Journal of Personality and Social Psychology, 64, 708-722.

Baumeister, R. F, Tice, D. M., \& Hutton, D. G. (1989). Self-presentational motivations and personality differences in self-esteem. Journal of Personality, 57, 547-579.

Buehler, R., Griffin, D., \& Ross, M. (1994). Exploring the "planning fallacy": Why people underestimate their task completion times. Joumal of Personality and Social Psychology, 67, 366-381.

Ericsson, K. A., \& Simon, H. A. (1980). Verbal reports as data. Psychological Review, 87, 215-251.

Gollwitzer; P. M. (1990). Action phases and mind-sets. In E. T. Higgins \& R. M. Sorrentino (Eds.), Handbook of motivation and cognition: Foundations of social behavior (Vol. 2, pp. 53-92). New York: Guilford Press.

Gollwitzer, P. M. (1991). Abwagen und Planen [Deliberation and planning]. Goettingen, Germany: Hogrefe.

Gollwitzer, P. M., Heckhausen, H., \& Steller, B. (1990). Deliberative versus implemental mind-sets: Cognitive tuning toward congruous 
thoughts and information. Journal of Personality and Social Psychol ogy, 59, 1119-1127.

Gollwitzer, P. M., \& Kinney, R. F. (1989). Effects of deliberative and implemental mind-sets on illusion of control. Journal of Personality and Social Psychology, 56, 531-542.

Heckhausen, H. (1986). Why some time out might benefit achievement motivation research. In J. H. L. van den Bercken, T. C. M. Bergen, \& E. E. J. De Bruyn (Eds.), Achievement and task motivation (pp. 7-39). Lisse, The Netherlands: Swets \& Zeitlinger.

Heckhausen, H., \& Gollwitzer, P. M. (1987). Thought contents and cognitive functioning in motivational versus volitional states of mind. Motivation and Emotion, 11, 101-120.

Janoff-Bulman, R., \& Brickman, P. (1982). Expectations and what people learn from failure. In N. T. Feather (Ed.), Expectations and actions: Expectancy-value models in psychology (pp. 207-237). Hillsdale, NJ: Erlbaum.

Jones, E. E., \& Gerard, H. B. (1967). Foundations of social psychology. New York: Wiley.

Kiesler, L. A. (1971). The psychology of commitment. New York: Academic Press.

Kulik, J. A., \& Mahler, H. I. M. (1987). Health status, perceptions of risk, and prevention interest for health and nonhealth problems. Health Psychology, 6, 15-27.

Nolen-Hoeksema, S. (1993). Sex differences in control of depression. In D. M. Wegner \& J. W. Pennebaker (Eds.), Handbook of mental control (pp. 306-324). Englewood Cliffs, NJ: Prentice-Hall.

Perloff, L. S., \& Fetzer, B. K. (1986). Self-other judgments and perceived vulnerability of victimization. Journal of Personality and Social Psychology, 50, 502-510.
Rosenberg, M. (1965). Society and the adolescent self image. Princeton, NJ: Princeton University Press.

Scheier, M. F., \& Carver, C. S. (1985). Optimism, coping, and health: Assessment and implications of generalized outcome expectancies. Health Psychology, 4, 219-247.

Taylor, S. E. (1989). Positive illusions: Creative self-deception and the healthy mind. New York: Basic Books.

Taylor, S. E., Aspinwall, L. G., \& Giuliano, T. A. (1993). Emotions as psychological achievements. In S. H. M. Van Goozen, S. H. M. Van de Poll, \& J. A. Sergeant (Eds.), Emotions: Essays on current issues in the field of emotion theory (pp. 219-239). Hillsdale, NJ: Erlbaum.

Taylor, S. E., \& Brown, J. D. (1988). Illusion and well-being: A social psychological perspective on mental health. Psychological Bulletin, 103, 193-210.

Taylor, S. E., \& Brown, J. D. (1994). Positive illusions and well-being revisited: Separating fact from fiction. Psychological Bulletin, 116, 21-27.

Weinstein, N. D. (1984). Why it won't happen to me: Perceptions of risk factors and susceptibility. Health Psychology, 3, 431-457.

Weinstein, N. D. (1993). References on perceived invulnerability and optimistic biases about risk of future life events. Unpublished manuscript, Rutgers University.

Wicklund, R. A., \& Brehm, J. W. (1976). Perspectives on cognitive dissonance. Hillsdale, NJ: Erlbaum.

Zuckerman, M., \& Lubin, B. (1965). Multiple Affect Adjective Checklist: Today form. San Diego, CA: Educational and Industrial Testing Service. 